\title{
Aesthetic Characteristics and Development of Chinese National Vocal Music
}

\author{
Wang Lei \\ Nanyang Institute of Technology, Nanyang, Henan, 473000
}

\begin{abstract}
Chinese national vocal music art also absorbs the Western vocal music art, the essence of Western vocal art for our use. In the 21st century, our national vocal music has made great progress in vocal theory, singing technique, singing form, vocal music teaching and vocal music creation. But also faced with some problems, with the progress of the times, economic development, people's ideas and ways of thinking are constantly changing updates, modern people tend to fast-food style, entertainment-style music, resulting in national vocal music in the Modern society suffered cold, mass basis is very weak, in the process of communication there are many problems. It can be said that the current national vocal music art is faced with the development of bottlenecks and the dilemma of the severe test, therefore, the study of Chinese national vocal art dissemination related issues is very necessary and has great research value, only a deep understanding of the dissemination of national art, And effectively grasp the basic characteristics of the dissemination of our national vocal art, and put forward effective strategies for this, in order to better dissemination of national vocal music art, in order to make national vocal art more shine.
\end{abstract}

Keywords: National Vocal Music, Aesthetic Characteristics, Musical Development

\section{Introduction}

First of all, the nationality, that is, the national characteristics of the Chinese nation is its most important characteristics; Secondly, folk and mass is a solid foundation, folk breed of national vocal music art, and for the development of 
national vocal music provides inexhaustible The source of the masses, the people created the national vocal music art, and to promote the development of national vocal art; and finally, eclecticism is its characteristics, the people are subjective initiative, with the development of the times, The masses selectively absorb more advanced forms of art and experience, and internalize them into the national vocal music art for the national vocal art. Therefore, the author believes that the national vocal music art of China includes both the musical works and the performance forms which express our people's thoughts and emotions with the national language familiar to the masses of our country, but also those musical works which are integrated into western vocal art, To national languages, national sentiments and feelings based on the formation of musical works and forms of performance.

\section{The Main Aesthetic Features of Chinese National Vocal Music Art}

For the characteristics of vocal art expression, as early as in ancient China there are related exposition. Chinese traditional theory of singing is a unique aesthetic value of ancient Chinese culture in the theory of heritage, contains a wealth of aesthetic thought. It can be said that one of the basic aesthetic principles of traditional Chinese singing theory. Singing emphasizes the emotional expression of singing art, that: love, is the inner spirit of the United States, is the dominant factor in singing art. Love for the sound of this, the sound of the shape of love. Sound is the external image, conditions and means of love; love to sound, sound to lyrical, sound and sound is the outward appearance of the singing art as a whole. Ming Wang Shizhen puts forward the aesthetic viewpoints of the opera and the emotion of emotion. The emotion expressed by the song is the emotion expressed by the song. Li Yu in the Qing Dynasty to send \# \# occasional exercise to explain the meaning of music in the proposed song should have the music. Quqing who, song of love also. This paper discusses the relationship between technique and content, performance and experience, and puts the experience and content in the first place, and puts forward the view that singing and body, facial expression cooperate with each other and convey the characters' emotion.

It is a kind of subjective psychological impulse that the author of the word obtains from the objective cognition and feeling, and then transforms this psychological impulse into the conceptual word or The emotional state of the word. The language of the lyrics of the ups and downs, cadence, the performance of the emotions have a certain supporting role. It is the integration and embodiment of the organic combination of melody, rhythm, rhythm, harmony, mode, tune, polyphony, musical form, orchestration and so on by means of the basic organizational means of music. My door can be said that the formation process of music that music creation process. Music is the movement of music in the form of time, and human emotional logic form is the symbol of human emotions. Music is the tone of the emotional life of copying, emotion, life, 
movement and emotions, composed of the meaning of music. ${ }^{1}$ The comprehensive requirements of the vocal music music tone creation and the language of the tone closely, in order to perfectly reflect the emotional content given to music creation. Sound and emotions arise from the emotional characteristics of works constructed under the principles of assimilation and adaptation. Vocal music must be performed through singing and singing in order to make the works in the form of text into the flow of sound exists in order to pass the emotional characteristics of the work to convey to the audience's sense of hearing. Accurate perception and grasp the emotions of the work, mood is the perfect performance of the cognitive basis of sound, on this basis to better express the implication of love song lyrics rich content.

From the creation of vocal music, the characteristics of ancient Chinese and foreign use are obvious. The creation of contemporary Chinese national vocal music, whether it is melody, rhythm, structure, harmony or orchestration, is extremely modern. At the beginning of the 20th century, the introduction of Western music not only brought the western vocal singing to the Chinese vocal music art, but also brought about the creation of Western music. The main contents of this period are the works of creation, Li Shutong, Huang Zi, Green Lord, should still be able to wait for people are struggling with the Western composition techniques and Chinese music style, charm of the combination of creation. With the study and research of western music by Chinese musicians, Chinese musicians have been amazed by the use of western music. The techniques and techniques of vocal music have become more mature. At the same time, the Chinese music workers in the use of Western composer technology on the traditional national vocal music adaptation and other aspects to experience the success of happiness, such works are numerous. Contemporary Chinese vocal art presents a promising situation in which Chinese national vocal music art and foreign vocal music art coexist well. Traditional vocal art, modern national vocal art, opera and folk art, as well as western vocal music, vocal music and other popular vocal music art forms to enrich the stage of Chinese vocal music art. Contemporary Chinese national vocal music in ancient times for the present, with the creative use of the ocean has a pleasing performance, embodies the integration of traditional and modern aesthetic thinking of music, the Chinese nation is a symbol of wisdom and wisdom.

The coexistence of the traditional style and the contemporary atmosphere is related to the content and form of the contemporary Chinese national vocal music art. From the external characteristics of the contemporary Chinese national vocal music art, the Chinese national vocal music art contains a lot of contents, which have different styles of singing methods and modern fashion performance forms and aesthetic characteristics. The so-called traditional style, refers to the Chinese national vocal music with a typical traditional Chinese music style and aesthetic characteristics of that part of the content, which is the Chinese national vocal music is different from other vocal art of the greatest features, including the previously mentioned traditional Singing characteristics, performance characteristics and aesthetic characteristics. Such as the words are singing round, rich and lively performance. The so-called fashionable atmosphere has the 
society and the times in the contemporary characteristics of the overall close contact. Everything is the successor of the previous era of tradition, but also the pioneers of the characteristics of this era. The art of vocal music has the characteristics of the times and is associated with the times. It is instantaneous and mobile. It will change with the passing of this era and the coming of the next era, but at the same time part of it will become the next age contains eternal content. From the vocal arts in Chinese vocal art scene, the singing of Chinese national vocal art is very fashionable both in the performance of the external figure and in the dress and make-up of the actor and the production of the musical instrument. Even the Western traditional singing method because of traditional Chinese vocal music with the Chinese art and the growth of this land has become more Chinese, closer to the aesthetic standards of the Chinese people by the Chinese audience is willing to accept. The traditional Chinese vocal music art is a kind of modern and modern art. It is a modern, eclectic and diverse art form. It emphasizes that the individuality is its main characteristic, but it is also adapted to traditional Chinese vocal music artworks in many cases.

\section{Strategies for the Dissemination of National Vocal Music Art}

At present, the spread of Chinese national vocal music is confronted with a new era environment, that is, modern environment filled with new media. Modern mass media, with its own superiority, has infiltrated into all aspects of people's daily work and study with overwhelming force. It is an important way for the masses to get all kinds of information and participate in economic and social life. To adapt to this trend, the spread of Chinese national vocal music began to use more and more modern mass media. Through the spread of modern mass media, making Chinese folk vocal music into people's lives, more conducive to the acceptance of the masses recognized, more likely to win the masses base. Modern mass media mainly for the network, television, radio, newspapers and so on.

Some national vocal TV talent show is not clear on their own positioning, awareness of their own fuzzy positioning. Will be confused with the pop music TV talent show, the program form to follow suit, the program content to imitate, put on the pop music TV show cover. In fact, the national vocal TV talent show the most important purpose is to the broad masses of the people of our nationspecific advanced vocal art and national vocal music culture. So the national vocal TV talent show to ensure that there is enough heavy national vocal music cultural connotation which runs through them. Of course, we are not opposed to the transformation of the form, but to avoid only a novel form, and lost the most important substance. Therefore, the national music TV talent show must be clearly positioning itself, starting from their own position, so as to ensure their own characteristics, in order to attract viewers, in order to ensure its long-term development.

The history of Chinese national vocal music has a long history and has a long history. After thousands of years of baptism, it began in the ancient times. It has been passed down from generation to generation in the process of historical 
evolution, accumulating and retaining the best and the best, And constantly enrich its theory and singing form, and to carry forward the same strain to continue the development of Chinese national vocal music in the heritage not only retains the form of performance, but also our national vocal music art theory and cultural connotation of the inheritance of the Down, therefore, our national vocal art to form its own unique aesthetic characteristics, the accumulation of its own heavy cultural connotations. China has a large number of nationalities, which means that our folk bears a wide range of national vocal music art, for example, our national opera, folk art, as well as various ethnic folk songs, and so on, they have their own characteristics. In addition, Chinese distinctive language features, combined with the differences in the pronunciation of different national languages, to promote the development of our national vocal music in the formation of a variety of vocal cavity system and singing.

\section{Conclusion}

In the modern society of diversified development, we should constantly innovate our national vocal music so that it not only has national characteristics, but also has the spirit of the times. At the same time, we should make full use of modern media, to spread more positive energy of the national vocal music culture; of course, but also for the development of our national vocal art to create a good environment, but the most important thing is that each of us should establish the correct Of the national vocal spread of consciousness, so that the national vocal music not only in our land of prosperity, but also out of the country, to the world. I believe in our joint efforts, our national vocal music will not only have been inherited and developed, but also timeless, shine a more gorgeous variety of light, so that people, so that the world attention.

\section{References}

[1] Liu Xuan. Cultural characteristics of contemporary Chinese national vocal music [J]. Music Exploration, 2010 (04)

[2] Qiu Lin. Analysis of the development process of green songs and its impact on the development of contemporary Chinese vocal music. [J]. Journal of Yunnan College of Arts, 2010 (03)

[3] Liao Hongmei. Analysis of contemporary Chinese national vocal music art aesthetic characteristics [J]. Vicissitudes, 2010 (06)

[4] Li Wei. The pioneering work of modern national vocal music - "Chinese modern national vocal theory" after reading [J]. People's Music, 2009 (02)

[5] $\mathrm{Wu}$ Bin. TV transmission and protection of the original ecological national culture [J]. Guizhou Ethnic Studies, 2008 (05) 